\title{
A propriedade, o espaço e o lugar do sujeito
}

\author{
The subject's propriety, space, and place
}

Jorge de Campos Valadares 1

1 Departamento de Saneamento e Saúde Ambiental, Escola Nacional de Saúde Pública Fundação Oswaldo Cruz. Rua Leopoldo Bulhões 1480 , 5 o andar, Rio de Janeiro, $R J$ 21045-900, Brasil. jorge@ensp.fiocruz.br

\begin{abstract}
This article deals with the "scenery", "horizons", and perspectives constituting the subject's place and situation from the psychoanalyst's limited perspective. Moving away from the body and its "em-bodiments" and places, many of which are institutionalized, including language itself, we look into such matters as velocity and other "con-jectures" associated with technique. In addition, we also consider the body and nature as a whole as sites of action and presentations, which in several scenes lead to representations of the world in view of the peculiarities in the subject's experiences. All virtualities, together with the "disembodiment of physical presence", add one more variable to our thoughts. Recent endeavors like the feminist and homeless movements have shed new light on our understanding of the desire to possess and govern a territory. Art (and here drama plays an essential role) seems to be the perfect system towards which perceptions and syntheses are directed in search of new concepts and directions for understanding (which, in turn, has recently undergone an unprecedented crisis). Still, we should point out that the latter issue, not dealt with in this article, will be discussed at a suitable opportunity. Key words Personal Space; Human Body; Philosophy
\end{abstract}

Resumo Partindo da limitação que impõe o lugar de fala do psicanalista, abordamos as questões relativas ao "cenário", dos "horizontes" e das "perspectivas" para o lugar, a Situação do Sujeito. Saltando do corpo, das "incorporações" e de seus espaços, muitos deles institucionalizados, incluindo aí o espaço da linguagem, chegamos, em nossas procuras, à situação das velocidades e outras armações (Gestell) da técnica. Nessa trajetória, pensamos o corpo e toda a "natureza" como sítios de presença e apresentações que, nos cenários diversos, dirigem-se para as representações de mundo, com base nas singularidades das vivências. As virtualidades, com a "descorporificação das presenças", trazem mais uma variável para a nossa reflexão. As novas lutas, como, por exemplo, a luta pela terra, a luta feminista, etc., têm trazido novas luzes para a compreensão do desejo de posse e de governo dos territórios. A arte, e, aqui, o teatro deve ocupar um lugar de destaque, parece ser o lugar ideal para onde todas as percepções e sinteses se dirigem em busca de novas elaborações e de uma nova direção para o entendimento, tendo este atingido uma crise sem precedentes. Mas esse último tema é assunto para ser mais desenvolvido em outra ocasião.

Palavras-chave Espaço Pessoal; Corpo Humano; Filosofia 


\section{A propriedade, o espaço e o lugar do sujeito}

Um psicanalista nunca deve se contentar em se dirigir ao outro sem, ao mesmo tempo, considerá-lo profundamente. Deve, por isso, se perguntar duas vezes ao abrir uma discussão pública. Habituado à penumbra, onde as questões se apresentam timidamente, principalmente quando são mais pertinentes, diante de luzes em profusão, corre o risco de omitir referências ao que não vê, ofuscado que está, pelo excesso de iluminação e, assim, optar por aquilo que mais brilha. Trabalhamos com incertezas e estamos sempre incertos. Assim, proponho-me a abordar o tema da propriedade, procurando deixar, de início, o mais claro possível, que apenas tento apontar indícios. São pequenas pistas que procurei seguir pelo meu trabalho de psicanalista e, como pesquisador, também na Instituição Pública de Saúde, na tese de doutoramento e pela minha própria experiência de homem profundamente ligado à terra, por ter nascido na roça, e que tem, para se destacar das paixões que o campo produz, que percorrer um caminho onde a Natureza teima muito ao abraçar a Cultura. Não podemos fugir de nós mesmos, como nos ensinou Freud (1976), e é a partir daí que devemos sempre re-começar.

Apesar da consciência de tanta complexidade, tenho, paradoxalmente, o sentimento de falar sobre o óbvio, embora me alente a certeza de que as verdadeiras questões, aí, no óbvio, se escondem. Na realidade, o que a minha experiência, situada entre o roceiro e o urbano, produz, é o sentimento e uma lógica muito fortes, a consistência mesmo, de algo muito pensado na psicanálise, de que o humano é constituído por um exílio fundador, um afastamento radical de raízes, que, paradoxalmente, estão fincadas numa terra da qual nunca saímos. Penso, com Robert Jay Lifton (Lifton, 1989), que esses compromissos, essas paixões - tão naturais mas, ao mesmo tempo, tão simples e tão complexas, na medida que são continuamente revisitadas, ao contrário do que diz um pensamento pretensamente científico - nos autorizam, de uma maneira especial a falar, pois uma razão, um pensar que delas, dessas paixões, é livre, só existiria como letra morta. A carne deve ser triturada e transformada nas tintas que escrevem o saber, com letras que devem sempre nos co-mover, nos emocionar, pois a vida é movimento, co-moção com o que ficou perdido, e com o que está aí, e não nos deixa esquecê-lo. Paixões por vivências abandonadas, por percursos, rastros de recordações, Erinnerung- spuren (Freud, 1972), que ficam como sintomas engastados na própria carne.

Com base, então, em uma "naturalidade", em um "bios", uma vida, uma pulsação, uma continuidade estranha ao caminho tortuoso e cheio de lapsos da Cultura, à qual chegará, ela, essa carne, vive uma descontinuidade, um lapso, um vacilo, diante do mundo, que a faz tremer ante o pensar. Nessa pulsação estão o amor próprio, o sentimento do si mesmo (Selbstgefühl-Freud, 1974a) e o sentimento do mundo. Ante o fato de dever encarar com invenções, teorias, esse lapso do saber/sabor (Barthes, 1977). É nesse sentido que Niestszche (1974:211) nos lembra Turenne, que diz: "carcaça tu tremes, pois tremerias mais ainda se soubesses onde vou te levar". O pensamento não se liberta da força da vitalidade da vida (PinaPrata, 1962). Isso quer dizer que a carne passa as suas pulsações para a energia do pensamento, o qual também vacila ou se impõe ante às determinações dela, da carne. E pode até continuar, como matéria, como carne no pensamento, agindo como um rolo compressor. A violência, as "explosões", as invasões, o assédio de toda espécie, os comportamentos comuns na atualidade, como situa Caporali (1999) e outros, são o testemunho disso.

Não se trata, pois, com o que quero dizer, de fazer um discurso puramente teórico. É o vivido, por isso irrepresentável, e em dois sentidos: pela dupla experiência com os espaços urbano e rural e pelo acompanhamento de perto, da dura realidade que as comunidades têm enfrentado, com as mudanças nas geografias desses espaços. Falo, aqui, de uma escrita no território - refiro-me ao território como o campo do biológico, estudado na sua condição de espacialidade, estando o corpo humano, à frente - como prolongamentos espaciais de sintomas.

Somente, portanto, falando das marcas da memória, inscritas pelo percurso do corpo, nas diversas dimensões do espaço é que produzimos uma cultura viva. É nesse sentido que essa fantástica mulher do cinema italiano, Liliana Cavani, nos diz que uma língua viva é aquela que é produzida por poetas vivos.

Não pretendo fazer ciência aqui, não somente por impropriedade (penso que a ciência deve ser somente feita em laboratórios), mas também por achá-la inútil ao todo do tema. Inútil ao con-junto (Suzammenhang - Freud, 1947) dos temas do viver humano. Não é o melhor, para a vida humana como um todo, superestimarmos detalhes. Penso que o poema, seu trabalho, sua produção, são mais propícios. E sabemos que a técnica, Tekné, e a produção poética do mundo, a Poiesis, até Platão, entre 
os gregos, eram a mesma coisa (Heidegger, 1990). Depois o homem foi obrigado a ir, cada vez mais velozmente, se fragmentando, para tentar viver e desfrutar do que a natureza, a physis, lhe oferece. Sabemos, com a maturidade de nosso poeta maior, que "o mundo é maior que o nosso coração”. A produção poética é, então, mais apropriada para falar da vida e de tudo que lhe está ligado, sobretudo para dizer algo sobre este palco, que é a terra, central para a cena humana, o seu des-envolvimento, os desnovelamentos das paixões.

Gostaria, para isso, de ser um poeta, mas como não o sou, tentarei, como posso, talvez como um sonhador e leitor apaixonado dos poetas, desencumbir-me dessa tarefa à qual me proponho. Entretanto, não nos esqueçamos que, aqui também, estamos sonhando. Calderán De La Barca (1992), com seu príncipe enjaulado, e Sigmund Freud (Freud, 1974b), com o que mostra da cultura como lugar do Mal Estar, não nos deixam dúvidas de que a vida é sonho. E se o sonho se realiza em velocidades, a realidade somente é vivida na lentidão (Santos, 1996). O sonho passa a ser pesadelo quando há urgência em sua realização; quando esquecemos de que a vida também é sintoma. É nesse sentido que a sabedoria popular diz que o pobre vive de teimoso. O tema é árduo e está ligado a um caminho árduo que é o da cultura. Não adianta pressa.

O corpo, como dizia, não podendo ek-sistir, estar fora da sua natureza, deve, então, fazer um percurso para se fazer cultura. Não há "Desejo" sem o seu fundamento no "Interesse do Ego” (Freud, 1974a), como não há corpo humano sem a língua, sem a letra, sem a cultura. Devemos nos afastar dessa cisão atual, que nos coloca diante da escolha impossível entre almas penadas e corpos pelados. Não podemos conhecer, explicar, "dar satisfação" de des-caminhos dos corpos, em sua procura a respeito do desejo. O Desejo existe às expensas do risco, e vive de escuridões. Mas porque não os conhecemos, a esses des-caminhos, não podemos dizer que não sejam um dia palmilháveis por algum saber. E parece ser esta uma posição da sabedoria: reconhecer a precariedade de nossos saberes, sem abandonar os sonhos. A pulsão de domínio, os "impulsos de empreendimento”, a impetuosidade, às vezes, nos fazem escorregar, sobretudo quando se trata dos domínios do saber. Não há saber imparcial, fora do domínio da corporalidade, do Interesse, que é o que funda o ego e suas "apreensões", sem o que seríamos almas penadas, sem "incorporações”, identificações e, portanto, sem ideais (Freud, 1974a).
O problema aparece quando essas incorporações, ao invés de evoluírem para a constituição do sujeito, servem para a sua devoração, pois o aprisionam em corporações. As identificações, as incorporações, são trabalhos do sonho, feitos pelo sujeito, no seio do seu grupo. Um grupo assim está mais interessado em fundações de contínuas mitologias que nas "instâncias práticas" com descobriu a análise institucional, sobretudo a partir do trabalho de René Lourau (Lourau, 1975) com as instituições.

O saber e a cultura são o que nos permitem estar juntos e, mesmo, poder olhar sempre novamente, um para o outro, isto é, respeitar-nos. "O saber é sabor", nos disse Roland Barthes (Barthes, 1977), e deve haver algum destino ou mesmo um desígnio, pelo qual a língua, este órgão cheio de voraz sideração, de desejo (desider-io) pela degustação do mundo, seja ao mesmo tempo, carne e letra. A sabedoria inicial do bebê sabe que tudo deve ser levado à boca, e o saber e nos mostra como isso, continuamente, se faz, isto é, como aprendemos o mundo, e como são nossas apreensões. Todo aprendizado exige o abandono de seguranças inventadas para o suporte do passado, e a freqüentação do desamparo, da percepção de que nosso passado está dentro de nós, desmanchado em sinais, rastros de recordações de algo que lembra o nosso lugar como um espaço vazio, como despedaçamento nas perdições do e no mundo. É lá, onde ele, o passado fracassou, que nós nasceremos. Quando nos disseram que criança deve se afastar da conversa de adultos, esqueceram-se, em seus sintomas, de que é a criança que pulsa em toda a des-organização do adulto. São infinitas as formas de organizar o mundo. E a criança não tem preconceito contra nenhuma delas. Essa criança insubordinada que está sempre dentro de nós procura, incessantemente, falar de prazeres, gostos que experienciou e aos quais confere valor, e ainda não viu reconhecidos, legitimados pela cultura.

Estou dizendo tudo isso para falar de fundamentos. Uma vez que nos acertamos aqui, nos fundamentos, o resto corre redondo. Depois nos dispersaremos de novo. Mas como em uma "mesa redonda”, estejamos juntos por algum momento. A história, aprendemos com Merleau Ponty (Ponty, 1984), somente pode ser apreciada da lacuna escancarada do presente, do prazer do convívio, das presenças. Depois é que se transforma em representação, em temas para as bibliotecas, para a arqueologia e para museologia. "O passado, que contemplo, foi dividido, foi presente. A ordem do saber não é única, não se fecha sobre si mesma e leva consigo, 
pelo menos, uma lacuna escancarada do presente. A história inteira é ação, e só a ação história" (Ponty, 1984:31).

Queremos dizer que, do ponto de vista da emoção, a questão da terra é fundamental. É histórica, para a cultura e para o sujeito. Os dois nascem juntos nesse palco, nessa cena. É uma questão vital e, se ela não evolui, nada evolui. E, como acontece nas infinitas questões do homem com a mulher, com quem contracena mais de perto, se as intermináveis relações entre o homem e seu cenário não evoluem, não evolui a cultura. E sabemos como é duro o cotidiano dos casais. É prazeroso mas é difícil.

Há, então, um casamento do homem com as espacialidades. As velocidades e a globalização, com seus des-caminhos, têm nos levado a crer num homem virtual, como se o corpo não precisasse de espaços para seu movimento e a alma não precisasse do des-envolver-se em suas paixões. A técnica, o fazer humano, exige uma contínua transformação do natural. É a busca de conforto pela diminuição do dispêndio de esforço. Essa busca, o homem irá jamais abandonar. Dizemos, com Ortega y Gasset (1963), que não existe um homem pré-técnico, uma vez que a técnica para o homem é uma tática de vida. A técnica nasce com a primeira distensão do corpo em direção ao mundo.

“A terra é do Homem. Não é de Deus nem do Diabo", lembrou-nos, depois de muitos outros, nosso grande cineasta Glauber Rocha, no seu filme Deus e o Diabo na Terra do Sol. E não andamos um passo, depois da carta do cacique americano, que se colocava perplexo diante da proposta de compra das suas "propriedades". A seiva das árvores, por onde ele representava a "vitalidade da vida", para empregar a expressão de Ortega, e que para o cacique Seattle era impensável vender, pois continha o sangue de seus antepassados, descrevendo, nas plantações, sua cultura, passa a ser, com a própria carta, ou com as suas letras, agora uma seiva da terra, a que todos estamos interessados em acompanhar. A voracidade do consumo, e do consumo de saber como mais consumir, levanos à vontade de posse das folhas e das raízes, antes mesmo de podermos degustar dos frutos, para "conhecermos", com as possibilidades de uma outra genética, o maior volume possível de "venda". Essa é a nova árvore do conhecimento. Ela mostra seu avesso enquanto mostra o avesso do homem. Uma representação que dê conta disso não é construída de maneira simples. Sabemos que a agressividade e a vontade de poder são constitutivas do psiquismo, que aumenta com o desenvolvimento da civilização (Freud, 1974b) e que por isso não cabe olhá-la de forma maniqueísta. Desde sempre ela foi constitutiva da vida emocional, como descreve Winnicott, quando trata de seu conceito de impiedade (ruthlessness - Winnicott, 1975).

$\mathrm{O}$ arquiteto Heberto Lira, cabeça do extinto Serviço Federal de Habitação e Urbanismo, desconfiando das velocidades e do globalismo, mostra-nos que o Movimento dos Trabalhadores Rurais Sem Terra é o único movimento social atualmente no Brasil. Os governos tentam fugir da impotência, e o "Social Welfare" das nações "em vias de desenvolvimento" luta para não somente se preocupar com a tarefa necessária, mas inglória, de apenas distribuir pratos de comida para famintos.

O Movimento dos Trabalhadores Rurais Sem Terra brasileiro não está preocupado, nos fundamentos mais profundos de seu projeto de gestão, com o fato de poder possuir terras. Está preocupado com "um novo projeto de gestão da Sociedade". Todo o seu trabalho de Formação, que é como situam a educacão, é, curiosamente, como o nosso, na psicanálise. É um exercício, uma tentativa contínua de invenção de um colorido para as espacialidades da vida, com tintas de sangue, com as quais vamos compondo um novo quadro, uma "bildung", como quer o pensamento ligado ao romantismo, pois a vida tensiona o corpo que, uma vez distendido, "compreende" o mundo. Não se trata de uma inteligência, uma leitura, que vai nos dizer o que é o mundo. Mas considero aqui, esta "compreensão", como na língua inglesa, com uma posição de domínio, de abrangência.

Ninguém se coloca diante do mundo sem uma curiosidade, uma vontade de degustação, de saber, de domínio, de apreensão com e do mundo, portanto. Por isso, as questões do território não são questões simplificáveis. É um lugar do sujeito, espaço de seu passe, de seus rituais de passagem e de acesso ao direito e à lei, pela forma com que nele opera, trabalha, obra, constrói, até mesmo seu próprio corpo. O “body building”, por exemplo, é uma armação, para empregar o termo de Heidegger (1990), um desvio de percurso, e um corpo de "academia" é uma simulação, um mimetismo, diante de um corpo de um operário. Devemos entretanto pensar as arm-ações como técnica um "truque para gozar" (Garcia, 1987), algo necessário à construção do sonho e da fantasia, e portanto, ao surgimento do sujeito.

Há, pois, uma produção dos corpos na cultura, onde as arm-ações, a Ge-stell, como situou Heidegger (1990), os truques, são, entretanto, atos centrais na geração da técnica apro- 
priada. Tanto a técnica de uma ocupação, de um assentamento, no habitat, como as técnicas de exclusão são arm-ações, truques. A palavra “ocupação" (Besetzung), usada por Freud, de origem militar, foi em português traduzida como "investimento". O sonho, o fantasma e a fantasia são truques, técnicas de gozo, a partir do investimento/ocupação em/com imagens, representações. O mimetismo, no corpo e no ambiente, também é uma tática, um "truque para gozar". Por isso, é inútil toda a tentativa de se ver as questões da propriedade como algo simplificável.

Enjaulado em uma cidade, como as atuais, o cidadão nos mostra os caminhos tortuosos para a cidadania. Isso tem levado os geógrafos a inventarem uma "geografia de lugar-nenhum" (Benko, 1994), situada em aeroportos, auto-estradas, motéis, etc., onde os descuidos do controle pelo instituído permitem, paradoxalmente, as armações que são necessárias para o surgimento do sujeito, como alguém que constrói seu nome a partir de seu próprio gesto.

O habitat, a habitação humana, lugar - reservo o termo lugar, para o espaço por onde o sujeito ensaia seus passos de não assujeitamento - por onde podem aparecer sujeitos, os não assujeitados, é toda uma outra coisa. É um lugar de relaxamento, de distensão, onde além dessa procura e possibilidade de transgressão há um legitimação de desejos singulares. Os próprios “Sem Terra”, com todas as preocupações e os cuidados, vêem o Jeca Tatu, no seu descanso, e também aquele que é o corrompido pela droga do consumo, o chamado "lumpem", no seu desbaratamento motor e de pensamento, como definitivamente excluídos de suas técnicas de inclusão. Seriam irrecuperáveis.

O sujeito, o grupo e seus espaços se fundam, excluindo. E sempre deverá haver uma luta de inclusão.

Como continuar essa luta? Contra o asilo onde o homem pode ser "normalizado" e o exílio impossível e necessário da condição vital, se é aí que o homem se funda. Nessa fundação, joga o outro no lugar daquilo a ser conservado como o mais estranho. O domínio do território, como é feito pelo animal, é interditado ao homem. O sujeito tem que lidar com o desejo de poder do outro e com o seu próprio. E sabemos, também, das lutas assassinas, mais fortes ainda entre irmãos, como aquela imortalizada por Schiller (1968) em sua peça "Os Arruaceiros”, em que dois irmãos se digladiam até a morte por uma herança.

Por isso a consciência é uma consciência possível, como disse Rosa de Luxemburgo. A propriedade e a apropriação dependem de de- sejos para os quais os objetos são lugares de situação, de ações situadas desenvolvidas pelo sujeito.

Os tempos de nossa ação no mundo são rejuntados nos espaços, que, como lugares de memória, produzem o que nos fica como reminiscências. Le Corbusier (1971) fala da estrada de pedra, do aqueduto, da muralha e do moinho de vento, como sendo ruínas comoventes. Vivemos delas, dessas memórias, tanto quanto de nossos projetos, em espaços ao mesmo tempo internos e externos. Não encontramos nada. Apenas reencontramos. Mas para nos reencontrarmos, para a volta àquilo que é perdido e sempre lembrado, pelo simples fato de nossa atenção estar situada no gesto cotidiano, precisamos do espaço do presente onde nos encontramos (Sami-Ali, 1974). Para irmos compreendendo o mundo, para representá-lo, precisamos de nos apresentar a ele, nele, e de nos movimentar em nossas paixões, tecer os tempos, re-unindo fazeres perdidos em nossa vida. Estando ligados às coisas deste mundo, sabemos que há uma diferença entre tomar e incorporar. Essa é a angústia em que nos colocamos desde a infância: comer o bolo ou olhá-lo todo, inteiro, sem poder desfrutá-lo (Fairbairn, 1940). Viver o mundo é poder destruí-lo e reconstruílo continuamente. E isso parece ser da ordem da tragédia, do destino, tal como é visto também por Freud. A apreensão diante da vida é, paradoxalmente, o seu objetivo. Destruímo-la e reconstruímo-la sempre. Não há computador que possa armazenar as técnicas dos fazeres humanos, pois o central, pelo que tem de disruptivo, em seu exílio, deve ser esquecido pelo homem, para ser relembrado com a cultura.

E quem não relembra, repete. E repete de uma forma em que o sistema motor substitui o pensamento. Essa parece ser a história dos fazendeiros que fazem churrascos, verdadeiros banquetes totêmicos, para comemorar o assassinato de um líder no campo, ou que ainda, colocam a prêmio cabeças de outros líderes, pelo preço de uma refeição, em um restaurante qualquer. As religiões e a arte tentam ritualísticas e espacialidades, por onde essa repetição se dê, de forma cada vez menos dolorosa.

Mas parece ser inútil um pensamento que se pretenda livre delas, dessas trágicas repetições. Estamos sempre repetindo. Como em um ensaio tentamos nossa situação no mundo. Quem participa da luta pelo ambiente nesses últimos trinta anos sabe disso. O que, além disso, podemos acrescentar? Talvez, timidamente, que podemos estar diante dos textos, como quem vai ao teatro assistir a uma cena estranha, sem ter a plena noção, o quanto, dela, é 
parte. Não podemos esquecer, entretanto, que, por isso mesmo, se trata de uma tragédia. Onde o central da tragédia, nos mostrou Whitehead (Hardin, 1968), é a distância sem remorso com que o ator se desloca na cena. Assim nos colocamos diante do ambiente e da "exploração" de seus recursos e do outro que necessita desses recursos para o ensaio do seu fazer e fazer-se. Com isso, termino o que queria dizer e faço a minha homenagem a Augusto Boal, mestre da representação e dos ensaios por onde, com a sua presença, a vida pode, então, se manifestar. Essa homenagem é uma coisa que queria fazer há muito tempo.

\section{Referências}

BARTHES, R., 1977. Aula. São Paulo: Editora Cultrix. BENKO, G., 1994. Geografia de lugar nenhum ou hiperglobalização. Breve exame do mundo Pós Moderno. In: Território, Globalização e Fragmentação (M. Santos, M. A. Souza \& M. L. Silveira, org.), pp. 247-251, São Paulo: Editora Hucitec/ Ampur.

CAPORALI, R., 1999. Ética e Educação. Rio de Janeiro: Editora Gryphus.

DE LA BARCA, C., 1992. A Vida é Sonho. São Paulo: Editora Scritta.

FAIRBAIRN, W. R., 1940. Estudos Psicanalíticos da Personalidade. Rio de Janeiro: Editora Interamericana.

FREUD, S., 1972. A Interpretação dos Sonhos. Rio de Janeiro: Imago Editora.

FREUD, S., 1974a. Sobre o Narcisismo. Rio de Janeiro: Imago Editora.

FREUD, S., 1974b. Mal Estar na Civilização. Rio de Janeiro: Imago Editora.

FREUD, S., 1976. Inibições, Sintomas e Angústia. Rio de Janeiro: Imago Editora.

GARCIA, C., 1987. Fantasma. Nem travessia, nem giro. In: Cadernos de Psicanálise, 6:119-120.

HARDIN, G., 1968. The Tragedy of the Commons. Science, 162:1243-1248.
HEIDEGGER, M., 1990. Die frage nach der technik. In: Vorträge und Aufsätze (M. Heidegger, ed.), pp. 9-41. Frankfurt: Pfulligen Günter Neske Verlag.

LE CORBUSIER, C.-E. F., 1971. Planejamento Urbano. Rio de Janeiro: Editora Perspectiva.

LIFTON, R. J., 1989. O Futuro da Imortalidade. São Paulo: Editora Trajetória Cultural.

LOURAU, R., 1975. Análise Institucional. Petrópolis: Editora Vozes.

NIETZSCHE, F., 1974. A Gaia Ciência. São Paulo: Editora Abril Cultural.

ORTEGA Y GASSET, J., 1963. Meditação da Técnica. Rio de Janeiro: Livro Íbero-Americano.

PINA-PRATA, F. X., 1962. Dialética da Razão Vital. Lisboa: Livraria Morais Editora.

PONTY, M., 1984. A Crise do Entendimento. São Paulo: Editora Abril Cultural.

SAMI-ALI, M., 1974. L'Espace Imaginaire. Paris: Gallimard.

SANTOS, M., 1996. Técnica, Espaço e Tempo. São Paulo: Editora Hucitec.

SCHILLER, F., 1968. Die Räuber/ Les Brigands. Paris: Aubier/Flamarion.

WINNICOTT, D. S., 1975. O Brincar e a Realidade. Rio de Janeiro: Imago Editora. 